\title{
Plutonium's new horizons
}

\author{
For historical reasons, plutonium brings to mind nuclear weapons. Jan Hartmann brings another side of \\ element 94 to attention, which features an upcoming trip to its eponymous celestial body.
}

$\mathrm{P}$ lutonium has had an undeniable influence on the twentieth century as a key contributor first to the end of World War II with the atomic bombing of Nagasaki in August 1945, then to the nuclear arms race of the Cold War.

After a false start in 1934, when Enrico Fermi mistook a mixture comprising barium, krypton and other species for element 94, plutonium was produced and isolated in 1940 by Glenn T. Seaborg and his colleagues. It was obtained through the bombardment of a uranium target with deuterium nuclei, but that success was kept secret until the end of World War II. The name 'plutonium' had already been suggested in 1816 for barium, after the Roman god Pluto, but abandoned. Seaborg gave it to element 94, this time continuing with the tradition of naming of the preceding actinides in the periodic table - neptunium and uranium - after the outermost planets of our Solar System ${ }^{1}$.

In the strictest sense, plutonium is naturally occurring: in 1951 D. F. Peppard isolated minute quantities of ${ }^{239} \mathrm{Pu}$ from uranium ore. But it makes up just $2 \times 10^{-19}$ per cent (by mass) of the lithosphere, so virtually all of the plutonium on Earth is produced artificially in nuclear reactors.

Otto Hahn discovered nuclear fission of uranium in 1938, sparking fears that Nazi Germany might be working on the development of nuclear weapons. This resulted in the setting up of the 'Manhattan Project' to develop nuclear weapons during World War II, during which plutonium was identified as a suitable fissile material. Kilogram-scale production of the new element began less than four years after its discovery. Germany surrendered in May 1945, ending the war in Europe before nuclear weapons were combat-ready. They were used against Japan instead, greatly accelerating the end of the war in the Pacific region. Despite the end of

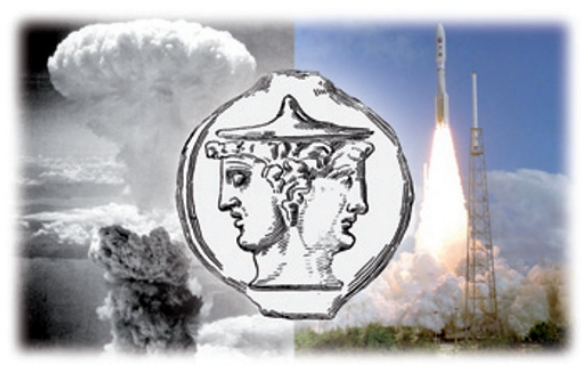

the war, large-scale production of plutonium continued in the nuclear arms race between the United States and the Soviet Union. Most of these nuclear stockpiles now necessitate research on the ageing process of plutonium metal; self-irradiation changes its physical properties over time in a way that remains poorly understood.

Yet there is more to plutonium than sheer destructive power: it exhibits surprising physical properties and fascinating chemistry. All of its known isotopes are radioactive, the most stable one $\left({ }^{244} \mathrm{Pu}\right)$ with a half-life of about 80 million years. Some other isotopes, most notably ${ }^{239} \mathrm{Pu}$, are capable of self-sustaining nuclear chain reactions, releasing enormous amounts of energy. It has six allotropic modifications, leading to its being called "a physicist's dream, but an engineer's nightmare" 2 . The different phases, close in energy, are prone to interconversion, leading to dramatic changes in properties with little stimulus. Its 'delta' allotrope is the only known metal with a negative thermal expansion coefficient, meaning that it contracts on heating.

Element 94 exists in the oxidation states + III to +VII, all intensely coloured, and is also the only known element for which four oxidation states (from $+\mathrm{III}$ to $+\mathrm{VI}$ ) can coexist in aqueous solution in nearly equal concentrations. In fact, a neutral, aqueous solution of $\mathrm{Pu}^{4+}$ reaches equilibrium of all four within a few hours ${ }^{3}$. In its most stable oxidation state, + Iv, plutonium tends to form coordination complexes, some of which are soluble in organic solvents such as diethyl ether or tributyl phosphate. The latter is used to separate plutonium from uranium in the 'PUREX' process.

Uses of plutonium include fuel for nuclear reactors, both for energy and for scientific research. In 2010, more than 13\% of the worldwide electricity demand was covered by nuclear reactors ${ }^{4}$. As a source of high-intensity neutron radiation, research reactors are invaluable tools, for example for neutron diffraction experiments. The non-fissile isotope ${ }^{238} \mathrm{Pu}$ is used in radioisotope generators, which have a long productive life and high energy density. This makes them suitable as sources of electrical energy for unmanned spacecraft such as the Mars Curiosity Rover and New Horizons. The latter is scheduled to reach Pluto and gather data on it in 2015, with instrumentation powered by $10.9 \mathrm{~kg}$ of ${ }^{238} \mathrm{PuO}_{2}$ (ref. 5). Thus, of all the elements named after celestial objects, plutonium is the only one so far to be sent to its astronomical namesake.

Plutonium might instead have been named after the two-faced Roman god Janus; its history lucidly illustrates the ambivalence of scientific inquiry. No scientific discovery is inherently good or evil. It is how it is used that decides how it will come to be seen.

This essay was selected as a winning entry in our writing competition; see http://go.nature.com/oil87X

JAN HARTMANN is a graduate student in the Department of Chemistry, RWTH Aachen University in Aachen, Landoltweg 1, 52074 Aachen, Germany.

e-mail: jan.hartmann@rwth-aachen.de

\section{References}

1. Römpp, H. et al. Römpp Chemie Lexikon Vol. 5 (Thieme, 1995)

2. Plutonium, an element at odds with itself. Los Alamos Sci. 26, 16-23 (2000).

3. Holleman, A. F. \& Wiberg, E. Lehrbuch der Anorganischen Chemie 101 edn (de Gruyter, 1995).

4. Another drop in nuclear generation. World Nucl. News (05 May 2010).

5. Final Environmental Impact Statement for the New Horizons Mission (NASA, 2005). 